\title{
Memórias de um regresso anunciado
}

\author{
Fernando Alberto Torres Moreira \\ Universidade de Trás-os-Montes e Alto Douro
}

\begin{abstract}
Resumo:
Ryszard Kapuscinski, jornalista polaco, convocado para testemunhar e relatar a "ponte aérea" do império colonial português, em Luanda, no ano de 1975, publica Mais um dia de vida, Angola 1975 ([1976] 2015), uma narração dos primeiros movimentos dos desterrados de Angola e dos primeiros passos para a descolonização, sob a ótica jornalística de alguém estrangeiro à trama colonial portuguesa. Trata-se de um "documento único" e de um "relato de viagem por uma cidade que apenas existiu três meses: a Luanda entre o êxodo português e a proclamação da independência pelo MPLA" (Kapuscinski 7). Mais de 40 anos depois do 25 de abril, Dulce Maria Cardoso, na obra ficcional O retorno (2012), apresenta o jovem Rui, nos mesmos últimos dias de Luanda em trânsito para uma pátria que não reconhece como sua, onde a problemática identitária é central. Numa análise das obras de Kapuscinski e de Cardoso, sob a ótica dos conceitos de memória e "desmemória", indaga-se sobre a relação entre história e literatura e as repercussões que esta possa ter no entendimento do passado colonial, ainda doloroso e controverso, nos tempos atuais.
\end{abstract}

Palavras-chave: memória, retorno, Dulce Maria Cardoso, Ryszard Kapuscinski

\begin{abstract}
:
Ryszard Kapuscinski, Polish journalist, called to witness and report on the "air bridge" of the Portuguese colonial empire in Luanda in 1975, publishes Mais um dia de vida, Angola 1975 ([1976] 2015), a narration of the first movements of the displaced people of Angola and the first steps towards decolonization, from the journalistic point of view of someone foreign to the Portuguese colonial plot. It is a "single document" and an "account of a journey through a city that only existed for three months: Luanda between the Portuguese exodus and the proclamation of independence by MPLA" (Kapuscinski 7). More than 40 years after April 25, Dulce Maria Cardoso, in the fictional work $O$ retorno (2012), presents young Rui, in the same last days of Luanda in transit to a homeland that he does not recognize as his own, where the problem of identity is central. In an analysis of the works of Kapuscinski and Cardoso, from the perspective of the concepts of memory and "desmemory", the relationship between history and literature is questioned and the repercussions this may have on the understanding of the still painful and controversial colonial past in contemporary times.
\end{abstract}

Keywords: memory, return, Dulce Maria Cardoso, Ryszard Kapuscinski 
É sobejamente conhecido que o processo de descolonização português se pautou por especificidades muito próprias, com destaque para a época em que ocorreu, claramente fora de tempo se comparado com o sucedido nos outros países colonialistas europeus (a exceção da então Rodésia não é comparável). De um modo ou outro, o pós-segunda guerra mundial impôs uma deriva de processos de fim de impérios que Portugal não quis acompanhar; houve conflitos mais ou menos violentos, houve também processos de negociação mais ou menos bem-sucedidos e houve, sobretudo, a intenção generalizada de uma saída honrosa que não ensombrasse as democracias europeias. Portugal estava fora deste filme que não reconhecia, auto-isolado na sua democracia orgânica que proclamava a unicidade do império do Minho a Timor. As soluções federativas que estiveram em cima da mesa tão pouco tiveram sucesso e a criação da ONU seria peça fulcral para a caminhada rumo à independência - Índia, Argélia, Congo, entre outros, são exemplos disso; a política externa e a cada vez maior internacionalização dos negócios aliados a uma opinião pública que rejeitava os imperialismos e sistemas capitalistas provocaram decisões inicialmente apenas consideradas.

Portugal, como afirmado, navegava noutras águas; o regime de Oliveira Salazar, apoiado numa eficaz máquina de propaganda, delineou um outro itinerário comandado pela aprovação do Ato Colonial, um documento que, na essência, proclamava a indivisibilidade de uma nação pluricontinental, expressão ideológica de um império secular. Assim seria até ao seu derrube em 25 de abril de 1974. A irredutibilidade dos mentores e responsáveis do Estado Novo, nesta matéria, inviabilizaria quaisquer tentativas de solução negociada para a independência das significativamente designadas como "províncias ultramarinas" que, sobretudo a partir do final dos anos 50, começou a ser reclamada, com particular incidência na ONU, onde novos países ex-colónias tinham já assento. Pior ainda: como afirma Pedro Aires Oliveira, "as abordagens de norteamericanos e outros aliados junto se Salazar para lhe sugerir uma saída controlada de África [...] permaneceram secretas e foram rejeitadas" (Oliveira 49). O Estado Novo, controlando ferozmente a informação, intoxicava o espaço público com propaganda ideológica que impedia um esclarecimento sobre o que acontecia noutros processos de descolonização ocorridos ou em curso. Foi até mais longe na sua verdadeira "religião colonialista" ao encomendar um trabalho valorativo da especificidade portuguesa colonial e imperial ao sociólogo Gilberto Freire que caucionava a originalidade harmoniosa, plurirracial e multicultural da colonização lusa- o luso-tropicalismo. Eduardo Lourenço apelidaria ironicamente essa teorização justificadora como "colonialismo inocente" (Lourenço 2014). A oposição interna a esta situação pouco efeito produziu; a pressão internacional é que se intensificava, se bem que a guerra fria tenha sido quase um bálsamo para as autoridades portuguesas.

O recurso à luta armada pelos movimentos nacionalistas das colónias acabaria por ser uma sequência lógica fase à teimosia salazarista que, nos anos 50 e 60, intensificou o movimento migratório de portugueses metropolitanos para os territórios africanas sob administração nacional. Marcelo Caetano e a sua denominada 'primavera marcelista' não alterariam esta situação, agora de guerra, e sem qualquer solução negocial à vista.

Isolado politicamente, Portugal também não escapou às consequências do choque petrolífero de 1973; somando a isto as debilidades de um país com uma economia pouco aberta e sustentando uma guerra em três frentes que lhe consumia os parcos 
recursos, enfrentar uma descolonização abrupta e absorver as respetivas consequências foi dose para canhão.

África foi a última etapa da migração e colonização portuguesas, o derradeiro quadro de um império que se fez e desfez em cinco séculos. De local de desterro até à terceira década do século XX (1934 foi o ano em que oficialmente deixou de funcionar como tal), os territórios africanos sob administração lusa ganhariam importância primeira na sequência do ultimato inglês de 1890, importância económica relevante, digase, à conta das matérias-primas. Mesmo que o Ato Colonial de 1930 refira, no seu artigo $2^{\circ}$, expressamente ser "essência orgânica da Nação Portuguesa desempenhar a função histórica de possuir e colonizar domínios ultramarinos", a colonização organizada e numerosa só sucederia no pós-guerra de 1939-45; até lá houve restrições legais e políticas, era necessária uma "carta de chamada" que, habitualmente só contemplava detentores de bens ou habilitações superiores, por exemplo. Entretanto, as pressões internacionais atrás referidas levaram Oliveira Salazar a uma operação de cosmética semântica em 1951: de país com colónias Portugal passou a nação una com províncias metropolitanas e ultramarinas, embora a livre circulação de pessoas e bens só tenha ocorrido em 1962 no então designado Espaço Económico Português. O fluxo migratório, contudo, haveria de decrescer, se bem que, paradoxalmente, e como observou Cláudia Castelo, ainda continuasse apesar de uma guerra colonial que se arrastava no tempo:

Dir-se-ia que os que vão chegando não acreditam que a 'unidade da nação pluricontinental portuguesa' possa ser quebrada. Aliás, as evidências materiais — prédios em construção, empresas iniciando atividade, jovens a constituir família - pareciam apontar para a perenidade do império. (Castelo 84)

Contudo, como é sabido, nem tudo o que parece é, tal como neste caso. Decerto que aqueles que continuavam a chegar às colónias, anestesiados por uma propaganda ideológica e por uma vitalidade económica estranha que contaminava os já residentes, não estiveram atentos às palavras escritas por um jornalista norte-americano no jornal $A$ Província de Angola, em 17 de fevereiro de 1961, poucos dias após o massacre de 4 do mesmo mês perpetrado pela UPA e que marcou o início da resistência nacionalista em Angola: "Os portugueses foram os primeiros a chegar e serão os últimos a sair". Aqui a importância é a irreversibilidade da saída que só o triunfo do "discurso do excecionalismo português" (Góis 89) mantinha ausente da consciência lusa. Os sinais do fim do terceiro andamento do império português iam-se acumulando e com eles um regresso anunciado das últimas naus, agora transformadas em navios transatlânticos e naves voadoras. Neles viriam entre 500 e 800 mil pessoas, vítimas de um processo de descolonização descontrolado e apressado, causado, essencialmente, pelo perfil ideológico do Estado Novo, como já assinalado e, após o 25 de abril, por uma forte pressão internacional em conjunto com uma mobilização intensa e pressionante de sentido anti-colonial existente nas colónias que o Portugal político metropolitano saído da Revolução dos Cravos não conseguiu suster.

Chegar com uma mão à frente e outra atrás foi a sina e consequência lógica desta verdadeira fuga e, como constata Christoph Kalter, "Essas chegadas do ano de 1975 acabariam por marcar as representações da época e as memórias subsequentes relativas ao que ficou conhecido como o "êxodo' dos retornados" (Kalter 105). Apesar de ser 
certo que, como refere o mesmo Kalter, esta vaga de regressos deve perspetivar-se no âmbito do já ocorrido noutros países europeus duas décadas antes ("uma população eurocolonial de entre cinco e sete milhões” (Kalter 107)), já não concordamos com ele quando entende que, por ter sido a última, isso tenha facilitado o modo de lidar com esse fluxo populacional que representou quase $10 \%$ do total metropolitano, até porque tudo aconteceu num curto período de tempo, sem qualquer negociação e, repete-se, numa altura de crise económica e de grande instabilidade política em Portugal.

Mais um dia de vida - Angola 1975, de Ryszard Kapuscinski, e O retorno, de Dulce Maria Cardoso, são duas abordagens memoriais, em formato diferente, do tempo vivido nos meses que antecederam a declaração de independência de Angola em 11 de novembro de 1975, apresentando o primeiro a visão de um jornalista estrangeiro (que se assume comprometido ideologicamente), e a segunda a perspetiva de quem viveu esse regresso forçado a Portugal, antes e depois, na pele de protagonista involuntário, travestido numa personagem de nome Rui que assume a narração; a obra de Dulce Cardoso, para além dos dias que antecederam a partida, foca, em igual medida, o choque do regresso à metrópole na condição de 'retornado'. Ambos os autores exprimem os dramas humanos (e civilizacionais) que percorrem o fim abrupto do império colonial português e, consequentemente, a situação verdadeiramente excecional vivida na Luanda pré independência onde coexistiram a debandada dos portugueses com um ambiente de guerra civil e luta pelo poder. Ryszard Kapuscinski resume numa frase o ambiente anárquico e caótico que se vivia: "Toda a gente combatia uma guerra privada, toda a gente estava por sua conta própria" (Kapuscinski 25).

A narrativa de Ryszard Kapuscinski, um "jornalismo intencionado", é, nas palavras de Pedro Rosa Mendes, "o relato de viagem por uma cidade que apenas existiu três meses: a Luanda entre o êxodo português e a proclamação da independência pelo MPLA" (Mendes 7).

Instalado no Hotel Tivoli, "a rebentar pelas costuras [...] cheio de gente que oscilava entre a agitação e a apatia, carregando trouxas atadas com cordas" (Kapuscinski 22-23) aquando da sua chegada, Ryszard Kapuscinski vê desfilar perante si toda a sorte de pessoas que ali se apinhavam numa espera desesperada de partida: um Sr. Silva, e a sua mulher, que trajava em permanência um fato quente onde escondia diamantes nas respetivas pregas, um casal de funcionários públicos ou a empregada de limpeza que se esforçava por manter a normalidade do estabelecimento são alguns exemplos. A atmosfera caótica vivida no hotel é também a da cidade onde se transpira de calor... e de medo:

As pessoas transpiram de calor e de medo. Havia um ambiente apocalíptico, uma expectativa de destruição [...] os boatos deixam toda a gente exausta, enervada, sem capacidade para pensar. A cidade vivia um ambiente de histeria e tremia de medo. (Kapuscinski 23)

Qualquer tentativa de organização defensiva no hotel terminava em discussão, consequência, segundo Ryszard Kapuscinski, da origem latina dos portugueses, uns "individualistas empedernidos, que por natureza não conseguem viver confinados, em comunidade" (Kapuscinski 29).

Ryszard Kapuscinski expõe a Luanda "branca", a "cidade de pedra" para onde "convergiam portugueses de todos os cantos de Angola" (Kapuscinski 27), apressados, que atafulham os hotéis e, cheios estes, se foram instalando junto ao aeroporto, em 
condições piores que o bairro negro aí próximo - era o resultado do desespero, de se querer ir embora o mais rápido possível, espelho de uma apatia generalizada e de uma "resignação desanimada" (Kapuscinski 28). Todos fugiam, na perceção de Ryszard Kapuscinski, "como se de uma doença infecciosa, como se de um ambiente pestilento, que não se consegue ver, mas mata" (Kapuscinski 39); queriam todos "escapar a tempo, antes que a primeira vaga de ar mortífero invada a cidade" (Kapuscinski 31). Cresceu, assim, por aqueles meses, "uma cidade nómada, sem ruas nem casas [...] à volta do aeroporto" (Kapuscinski 27).

Entretanto, o regresso continuava a preparar-se na "cidade de pedra", onde "os hospitais estavam fechados e os médicos tinham ido todos embora", e também "todos os serralheiros tinham partido" (Kapuscinski 20-21); os que ainda ficavam reuniam os bens possíveis em caixotes de madeira para futuro transporte dando origem a uma outra realidade arquitectónica temporária; Ryszard Kapuscinski é bem impressivo na descrição dessa situação:

Dentro da Luanda de betão armado e tijolos, erguia-se uma nova cidade de madeira [...] gradualmente, noite após noite, a cidade de pedra transferiu o seu valor para a cidade de madeira [que] foi levada de camião para o porto. (Kapuscinski 31; 34)

A cidade esvaziava-se de bens e pessoas; a malha que sustentava o seu funcionamento orgânico, a sua existência, desfazia-se, anarquizando-a: os polícias já foram embora, os bombeiros também, assim como os homens do lixo; finalmente saíram barbeiros, canalizadores, eletricistas, carteiros e porteiros: a cidade transformava-se num "esqueleto seco" de onde até um dia os cães, que abandonados pelos donos fugidos percorriam as ruas em bandos, desapareceram (Kapuscinski 42; 44; 47).

A maior parte desta "cidade de madeira" mudou-se para as margens do Tejo, em Lisboa, onde Ryszard Kapuscinski a revisitou, regressado no último avião da ponte aérea; aí ele viu "montanhas impressionantes de caixotes, empilhados até alturas perigosas, sem qualquer sinal de movimento, abandonados, como se não pertencessem a ninguém" (Kapuscinski 37). Eram as "sobras do império", expressão acertada de Belchior, uma das personagens de $O$ retorno, de Dulce Cardoso, "a apodrecer no mesmo sítio de onde o império começou" (Cardoso 188). Ryszard Kapuscinski informa também sobre outras sobras do império de cinco séculos, arrumadas, alinhadas, frente à cidadela de Luanda, na véspera da independência:

Um camião andou pela cidade nesse dia a retirar as estátuas de conquistadores portugueses de seus pedestais. Os governadores e os generais, os viajantes e os exploradores foram reunidos em frente da cidadela de Luanda e arrumados em duas filas de granito castanho. (Kapuscinski 156-157)

A família protagonista de $O$ retorno, de Dulce Cardoso, viveu intensamente toda a situação descrita por Ryszard Kapuscinski; ela é bem o exemplo do modelo e estratégia de colonização salazarista, desse anestesiamento que contaminou quase todos, dessa ideologia que se investia de uma missão única civilizacional: Mário, o pai, um dos imigrados pós guerra, mesmo perante a derrocada iminente, com o caos a instalar-se e apesar de avisos amigos, insistia na passagem de ano de 1974 para 1975: "vai correr tudo bem, vamos construir uma nação, pretos, mulatos, brancos, todos juntos vamos construir a nação mais rica do mundo" (Cardoso 12). Glória, a mãe, vive em permanência a 
duplicidade da sua condição de metropolitana e de imigrada no império numa "terra que a adoeceu" (Cardoso 11) e da qual, na pressa do empacotamento de alguns pertences, nada quer trazer de recordações aí construídas. Os filhos, Milucha e Rui, são portugueses de Angola, educados na mitificação de uma metrópole que apenas conhecem como um ponto pequeno de um mapa do império decalcado sobre a Europa. Rui, personagem principal, é esclarecedor sobre esta vivência mítica: "Foi esquisito pisar na metrópole, era como se estivéssemos a entrar no mapa que estava pendurado na sala de aula" (Cardoso 76).

Tal como Ryszard Kapuscinski, a personagem Rui expõe o esvaziamento progressivo da cidade e a consequente anarquia amplificada pelo abandono e pela disputa do poder entre as diferentes fações políticas dos movimentos de libertação: "Já todos se foram embora. Os meus amigos, os vizinhos, os professores, os donos das lojas, o mecânico, o barbeiro, o padre, todos. Nós também já cá não devíamos estar" (Cardoso 11). Por esta altura, Mário, o pai, já não é o resiliente do início de 1975, absorvido por uma crença que o afastava da nova realidade que se impunha —ele é um revoltado que intenta queimar os bens que ficam antes de partir; o jovem Rui, na espera da partida anunciada, constata a evidência: "Ainda que gostemos de nos enganar dizendo que voltamos em breve, sabemos que nunca mais estaremos aqui. Angola acabou. A nossa Angola acabou" (Cardoso 14). O seu convencimento resulta da atmosfera que os envolve: "os tiros e os morteiros não param, os pretos continuam a vir de todo o lado e os brancos a irem-se embora [...] a cidade ficando mais vazia de dia para dia" (Cardoso 33).

A família acabaria por partir, com parcos haveres, sem o pai que um episódio dramático reteria em Angola, incontactável, por muitos meses. Como tantas outras, sem referências na metrópole, foram transitoriamente alojados num hotel, incógnitos num país que se dizia ser o seu: "Ser retornado de hotel também é mau porque quer dizer que não há sequer um familiar que goste de nós o suficiente para nos querer em casa" (Cardoso 124). Faziam parte dos destroços e estilhaços de um império acabado, "um império cansado, a precisar de casa e de comida, um império derrotado e humilhado, um império de que ninguém quis saber" (Cardoso 86). As sobras do império não estavam só simbolicamente alinhadas em caixotes junto ao Tejo; os restos do império eram sobretudo estes regressados, acantonados e amontoados em hotéis, pensões ou parques de campismo, que os metropolitanos olhavam de viés.

O retorno é uma narrativa memorial de um regresso anunciado que, vestida de ficção, não deixa de ser um "testemunho num sentido amplo, abrangendo o não intencional, aquilo que, não transmitindo uma visão estruturada, pode servir de base a uma história alternativa que não se deixe engodar pelas lógicas dominantes" (Rossa and Ribeiro 85). Aplica-se, aos textos aqui abordados, a conclusão assertiva que, sob a titulação de "retorno cabisbaixo", Fernando Dacosta expôs na sua obra Os Retornados Mudaram Portugal, publicada em 2013:

A nossa debandada de África [...] constitui uma das grandes tragédias da história contemporânea, uma história trágico-aérea-marítima que vazou nos portos de Alcântara e Portela populações em situações-limite. (Dacosta 30-31)

Contudo, a verdade dramática desta descolonização pouco exemplar (mas podia ser outra, dadas as circunstâncias?) é também devedora da nossa falta de memória 
histórica, do pouco que o Estado Novo aprendeu com o passado que apenas quis glorioso. De facto, concordando com Dacosta,

o retorno começou [...] muito antes de 1974. Há 400 anos, saídos do Norte de África, desembarcaram no Algarve e em Lisboa, os primeiros retornados do império: militares, comerciantes, missionários, mulheres, crianças, escravos, vindos após a entrega de Safim e Azamor, Arzila e Santa Cruz. (Dacosta 36)

O piedoso D. João III, noutras matérias tão imprevidente, teve a clarividência para decidir no sentido que séculos mais tarde faltaria a Salazar e Caetano, pois por essa altura já em Marrocos se haviam criado duas gerações de portugueses, isto é, esposas, filhos, famílias, elementos da administração e até, fortalezas a demolir.

Em texto produzido entre os anos de 19611963 (que os tempos de censura não permitiram ver a luz do dia), mas só publicado em 1976, Eduardo Lourenço enunciava o singularismo do facto colonial português ser "a mais espetacular boa-consciência colonial que a História regista" (Lourenço 329), um fenómeno cujas consequências e amplitude, ainda segundo o mesmo ensaísta, constituem "uma das faces da nossa tragédia em curso" (Lourenço 329). Lourenço escrevia ao tempo do início da guerra em Angola e pré-anunciava um retorno incontornável, apesar da sua convicção de que nos tínhamos esquecido que o império era resultado da colonização ou, como conclui, do "encontro com outrem sob uma forma que não exclui, nem excluiu a violência" (Lourenço 329); por isso, continua, "O que é verdadeiramente original no comportamento português é o silêncio" (Lourenço 328), um comportamento de então como de agora! É decerto por essa razão que, como notou Ângela Ferreira, mais do que a questão do 'retorno' o que está em causa, ainda hoje, é o processo de descolonização portuguesa (sem esquecer as suas causas, diríamos nós), "mal pensado e mal gerido", um "processo que ainda continua indevidamente analisado ou avaliado e muito menos objeto de uma tão necessária comissão de "verdade e reconciliação"” (Ferreira 362).

Acima de tudo, é urgente uma descolonização efetiva das mentes (o Primeiroministro português falava há pouco tempo da necessidade de descolonizar a descolonização), assumir que o exílio externo é uma marca identitária do povo português com tudo o que envolve e que, para isso, é necessário resgatar silêncios pela memória. É neste contexto que as obras de Ryskard Kapuscinski e Dulce Cardoso seguramente contribuem para esse estabelecimento/resgate da memória enquanto instrumento cultural, social e identitário, com vista ao entendimento do passado colonial, ainda doloroso e controverso, é certo, mas necessário.

\section{Referências bibliográficas}

Ato Colonial. Decreto-lei nº18 570. 8 de julho 1930.

Cardoso, Dulce. O Retorno. Lisboa: Tinta da China, 2011.

Castelo, Cláudia. "Migração Colonial para Angola e Moçambique (séculos XIX-XX)". Retornar - Traços de memória do Fim do Império. Ed. Elsa Peralta, Joana Oliveira and Bruno Góis. Lisboa: Edições 70, 2017. 121-140.

Dacosta, Fernando. Os Retornados Mudaram Portugal. Lisboa: Tinta da China, 2013. 
Ferreira, Ângela. "Os limites do poder do Padrão dos Descobrimentos e o Retorno ao Arquivo". Retornar - Traços de memória do Fim do Império. Ed. Elsa Peralta, Joana Oliveira and Bruno Góis. Lisboa: Edições 70, 2017. 353-362.

Góis, Bruno. "Retornar à pergunta "O que faz partir as gentes?". Retornar - Traços de memória do Fim do Império. Ed. Elsa Peralta, Joana Oliveira and Bruno Góis. Lisboa: Edições 70, 2017. 85-98.

Jornal A Provincia de Angola. 17 fevereiro 1961.

Kalter, Christoph. "Gente Pós-colonial: quem eram os retornados?”. Retornar - Traços de memória do Fim do Império. Ed. Elsa Peralta, Joana Oliveira and Bruno Góis. Lisboa: Edições 70, 2017. 101-120.

Kapuscinski, Ryszard. Mais um dia de vida - Angola 1975. Lisboa: Tinta da China. 2013.

Lourenço, Eduardo. "Do Colonialismo como nosso impensado". Retornar - Traços de memória do Fim do Império. Ed. Elsa Peralta, Joana Oliveira and Bruno Góis. Lisboa: Edições 70, 2017. 329-341.

Mendes, Pedro Rosa. "Prefácio". Mais um dia de vida - Angola 1975. Ryskard Kapuscinski. Lisboa: Tinta da China. 2013.

Oliveira, Pedro Aires. "As condições políticas e sociais da Descolonização". Retornar Traços de memória do Fim do Império. Ed. Elsa Peralta, Joana Oliveira and Bruno Góis. Lisboa: Edições 70, 2017. 47-62.

Rossa, Walter; Margarida Calafate Ribeiro. Patrimónios de Influência Portuguesa-Modos de olhar. Coimbra: Imprensa da Universidade de Coimbra, 2015. 